Volume 2

\title{
PRACTC: Practice Readiness Academic Clinical Training Collaborative -- Gap Analysis to Advance Clinical Training for Nurse Practitioner Students
}

\author{
Jennifer Hartlaub \\ Mary Ann Muzi \\ M. Jamie Cairo \\ John R. Brill \\ James Weese \\ Kristin Rivera \\ Susan Hafemann \\ Ann M. Rohrer \\ Julia Schumacher \\ Terri L. Vandenhouten
}

Follow this and additional works at: https://aah.org/jpcrr

Part of the Health and Medical Administration Commons, Medical Education Commons, and the Nursing Commons

\section{Recommended Citation}

Hartlaub J, Muzi M, Cairo M, Brill JR, Weese J, Rivera K, Hafemann S, Rohrer AM, Schumacher J, Vandenhouten TL. PRACTC: Practice Readiness Academic Clinical Training Collaborative -- Gap Analysis to Advance Clinical Training for Nurse Practitioner Students. J Patient Cent Res Rev 2015;2:211.

http://dx.doi.org/10.17294/2330-0698.1236

Published quarterly by Midwest-based health system Advocate Aurora Health and indexed in PubMed Central, the Journal of Patient-Centered Research and Reviews (JPCRR) is an open access, peer-reviewed medical journal focused on disseminating scholarly works devoted to improving patient-centered care practices, health outcomes, and the patient experience. 
consecutive patients (mean age $67 \pm 14.15$ years, $50.72 \%$ women) with ALI (Rutherford category IIb) who underwent CDT only (57.9\%) or CDT plus bailout Angiojet mechanical thrombectomy $(36.78 \%)$ at Aurora St. Luke's Medical Center from January 2004 to October 2014. Data were collected from electronic medical records, procedures reports, laboratory data and billing codes. Continuous variables were expressed as means \pm standard deviation and range; categorical variables were expressed as frequency count and percentage.

Results: Sites of target vessel for CDT were native vessel arterial thrombosis $(68.11 \%)$ and vascular bypass graft thrombosis $(27.5 \%)$. Reestablishment of blood flow and clinical success was achieved in $75.4 \%$ of patients, while limb salvage at 30 days was achieved in $87.1 \%$. Amputation at 30 days occurred in $12.9 \%$. Surgical embolectomy was required in $15.9 \%$, and lower extremity bypass surgery was required in $8.7 \%$. Time to lysis was $26.12 \pm 18.6$ hours. Bleeding complications that required blood transfusion occurred in $21 \%$ and hemorrhagic stroke in $1.44 \%$.

Conclusion: Catheter-directed thrombolysis for acute limb ischemia with symptoms less than 14 days (Rutherford category $\mathrm{Ilb}$ ) in native artery or bypass graft thrombosis has high immediate clinical success rate and very high limb salvage rate at 30 days. CDT is a reasonable minimally invasive alternative option to emergent surgical revascularization.

\section{PRACTC: Practice Readiness Academic Clinical Training Collaborative - Gap Analysis to Advance Clinical Training for Nurse Practitioner Students}

Jennifer Hartlaub, Mary Ann Muzi, M. Jamie Cairo, John R. Brill, James Weese, Kristin Rivera, Susan Hafemann, Ann M. Rohrer, Julia Schumacher, Terri L. Vandenhouten

Departments of Family Medicine and Academic Affairs, Aurora UW Medical Group; Departments of Oncology and Medical Education, Aurora Health Care

Background: Multiple factors have created a perfect storm of health care provider shortages in the United States. Advanced practice registered nurses (APRNs), long established as high-quality, cost-effective health care providers, are meeting health care needs across the nation in a variety of settings, and in Wisconsin will be needed to augment the primary care workforce. With $5.7 \%$ of its registered nurses credentialed as APRNs, Wisconsin lags behind the national average of $8.7 \%$. However, current capacity to educate this workforce is strained, requiring innovative data-driven clinical education models.

Purpose: To identify gaps in the current clinical educational framework for nurse practitioner (NP) students within the integrated health system.

Methods: Multiple data sources were used including NP core learning goals achievement, current continuum education/training experience models, health care system stakeholders' perspectives, and advanced practice provider hiring targets for 2015. NP-partnering universities' curricula and experiences of placing students within the integrated health system were reviewed. Analysis was conducted by an interprofessional team to identify gaps.

Results: Four gaps were identified: 1) structured learning and assessments focused on value-based care models (e.g. population, chronic disease) and tracking competencybased milestone achievement; 2) streamlined NP student placement system and onboarding through centralized onestop infrastructure; 3 ) interdisciplinary education to emulate theworkplacein which practice-ready graduates willbeplaced; and 4) number of preceptors with skills and knowledge regarding NP educational curriculum and competencies.

Conclusion: Systematic gap analysis will guide NP student placement and education at large Midwestern integrated health system. A structured clinical academic partnership with local university NP programs (PRACTC) that addresses preclinical preparedness, a structured student placement process, coordinated clinical experiences, preceptor development strategies and a diversity strategy provides a mechanism for accomplishing these goals.

\section{$\beta$-Thujaplicin: A Soil Antifungal}

\section{Dennis J. Baumgardner}

Department of Family Medicine, Aurora UW Medical Group; Center for Urban Population Health

Background: $\beta$-thujaplicin ( $\beta$-Th), also known as hinokitiol, naturally occurs in cedar mulch, is found in personal care products and has in vitro antitumor activities. It is antibacterial and antifungal, but has not been tested on soil. Scedosporium apiospermum (Sce) is an emerging "extremophile" fungal pathogen found in built outdoor environments.

Purpose: Pilot $\beta$-Th as "natural" soil antimicrobial or for isolation of extremophiles, and to explore $\beta$-Th resistance as selective advantage to Sce in mulched landscape.

Methods: A variety of outdoor and indoor environments were used for 2 sets of 24 paired soil samples. Soil/H20 slurry $(0.1 \mathrm{ml})$ was spread on Sabouraud dextrose agar with titrated $\beta$-Th levels of $0,25,250$ and $500 \mathrm{mg} / \mathrm{L}$ at $20^{\circ} \mathrm{C}$. Fungal and bacterial growth was semiquantitated with 4-point Likert scale. Wilcoxon signed rank test was used for comparison. A local soil Sce isolate was tested on each $\beta$-Th concentration. Results: There was no significant inhibition of total bacterial growth at $\beta$-Th $250 \mathrm{mg} / \mathrm{L}$ (mean 1.7/4) or $500 \mathrm{mg} / \mathrm{L}$ (mean 1.7) compared to plain Sabouraud dextrose agar (mean 1.6). Purple bacteria seemed to be selected for by $\beta$-Th. Fungal inhibition was essentially complete, similar, and significantly different from no $\beta$-Th (mean 3.4/4) at levels of 250 (mean 0.1 ) and $500 \mathrm{mg} / \mathrm{L}$ (mean 0.0). There was no significant fungal inhibition at $25 \mathrm{mg} / \mathrm{L}$ (mean 3.2 , second set samples). Similarly, Sce was completely inhibited at 250 and $500 \mathrm{mg} / \mathrm{L}$, but not inhibited at $25 \mathrm{mg} / \mathrm{L}$.

Conclusion: In vitro, $\beta$-thujaplicin profoundly, but 